January 2013

\title{
Cultural Identity And Behavioral Health Risk In Northern Plains American Indian Adolescents
}

Wanmdiwi Jessi Rose

\section{How does access to this work benefit you? Let us know!}

Follow this and additional works at: https://commons.und.edu/theses

\section{Recommended Citation}

Rose, Wanmdiwi Jessi, "Cultural Identity And Behavioral Health Risk In Northern Plains American Indian Adolescents" (2013). Theses and Dissertations. 1475.

https://commons.und.edu/theses/1475

This Thesis is brought to you for free and open access by the Theses, Dissertations, and Senior Projects at UND Scholarly Commons. It has been accepted for inclusion in Theses and Dissertations by an authorized administrator of UND Scholarly Commons. For more information, please contact und.commons@library.und.edu. 


\title{
CULTURAL IDENTITY AND BEHAVIORAL HEALTH RISK IN NORTHERN PLAINS AMERICAN INDIAN ADOLESCENTS.
}

\author{
WanmdiWi J. Rose
}

Bachelor of Arts, University of Montana, 2004

\author{
A Thesis \\ Submitted to the Graduate Faculty \\ of the \\ University of North Dakota \\ in partial fulfillment of the requirements \\ for the degree of \\ Master of Arts
}

Grand Forks, North Dakota

May

2013 
This thesis, submitted by WanmdiWi Rose in partial fulfillment of the requirements for the Degree of Master of Arts from the University of North Dakota, has been read by the Faculty Advisory Committee under whom the work has been done and is hereby approved.
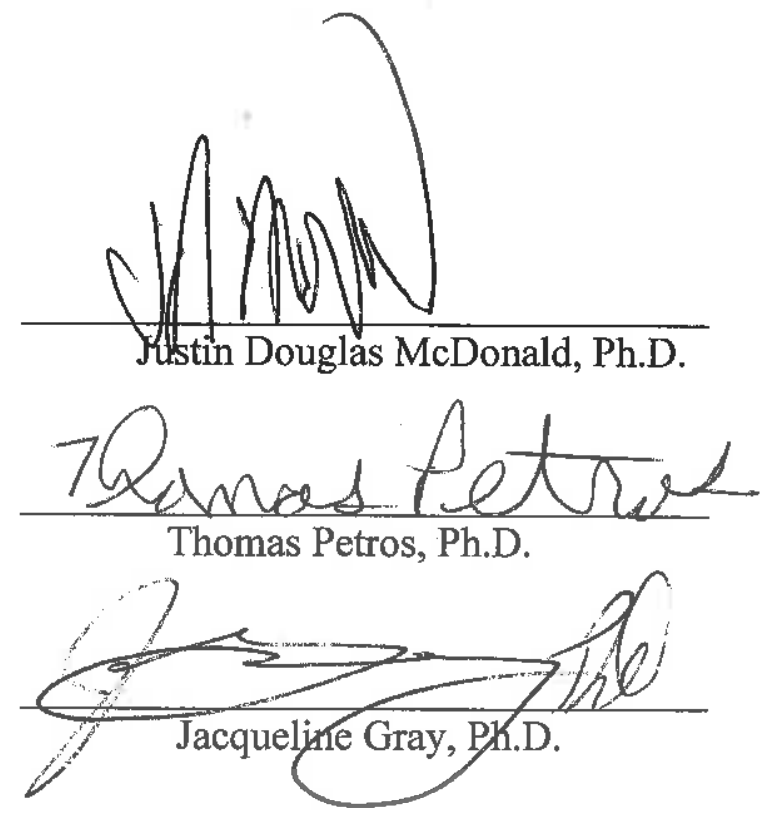

This thesis meets the standards for appearance, conforms to the style and format requirements of the Graduate School of the University of North Dakota, and is hereby approved.

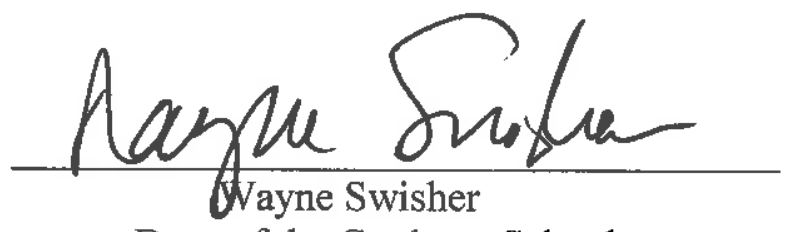

Dean of the Graduate School

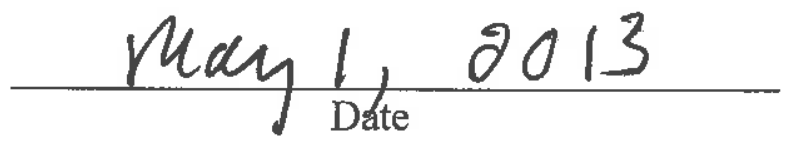




\section{PERMISSION}

Title Cultural Identity and Behavioral Health Risk in Northern Plains American Indian Adolescents.

Department Psychology

Degree Master of Arts

In presenting this thesis in partial fulfillment of the requirements for a graduate degree from the University of North Dakota, I agree that the library of this University shall make it freely available for inspection. I further agree that permission for extensive copying for scholarly purposes may be granted by the professor who supervised my thesis work or, in her absence, by the chairperson of the department or the dean of the Graduate School. It is understood that any copying or publication or other use of this thesis or part thereof for financial gain shall not be allowed without my written permission. It is also understood that due recognition shall be given to me and to the University of North Dakota in any scholarly use which may be made of any material in my thesis.

Signature WanmdiWi J. Rose

Date $\quad \underline{1 / 18 / 2013}$ 


\section{TABLE OF CONTENTS}

LIST OF TABLES..........................................................vi

ACKNOWLEDGMENTS ................................................. vii

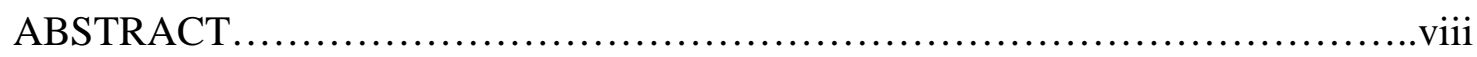

\section{CHAPTER}

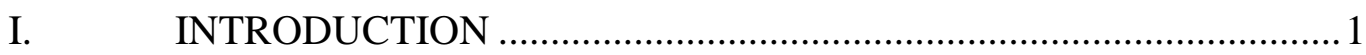

Studies on Risk and Protective factors for American Indians .........2

Risk Assessment .............................................................. 4

Adolescent Mortality and Health-Risk Behaviors ....................... 6

American Indian Adolescent Mortality

and Health Risk Behaviors.................................................... 8

American Indians of the Northern Plains:

beliefs, worldviews, attitudes, and acculturation .......................... 10

Protective Factors and Resilience ............................................... 12

American Indians of the Northern Plains.......................13

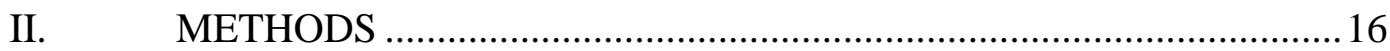

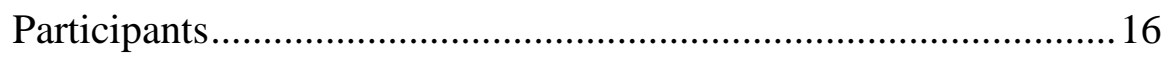

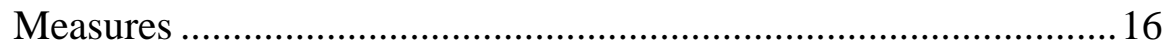

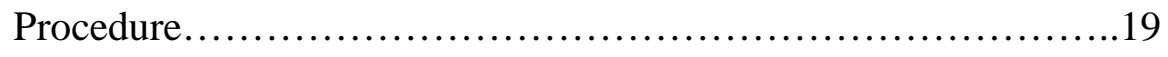

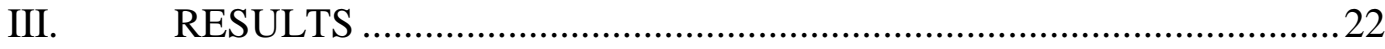


Descriptive Characteristics of Sample ........................................22

Group Comparisons......................................24

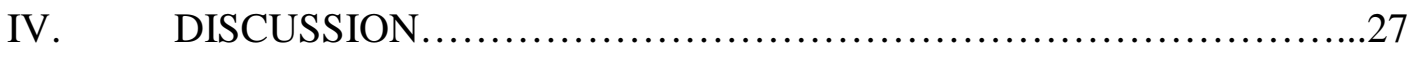

Limitations of the Current Study...............................29

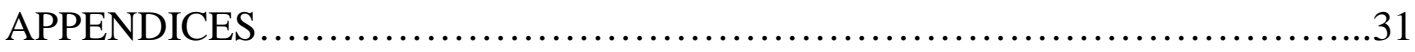

REFERENCES...................................................... 35 


\section{LIST OF TABLES}

$\begin{array}{lll}\text { Table Page } & \end{array}$

1. Means and Standard Deviations................................................... 23

2. Pearson Correlations Between Subscale Measures...................26 


\section{ACKNOWLEDGMENTS}

I wish to express my sincere appreciation to the INPSYDE program and the members of my advisory committee. Thank you for your guidance and encouragement during my time in the clinical psychology doctoral program at the University of North Dakota. 
To Bradley, KimimilaWi, and Carson 


\begin{abstract}
The purpose of this study was to determine if Northern Plains AI adolescents identifying oneself as being "traditional' or "non-traditional" as measured by the Northern Plains Bicultural Inventory III (NPBI-III) would affect health-risk behavior scores as measured by the Youth Risk Behavior Survey (YRBS). It was hypothesized that American Indian adolescents identifying as traditional would have lower health- risk behaviors and that cultural identification would influence health-risk behaviors between males and females.
\end{abstract}

Northern Plains AI adolescents ( $\mathrm{N}=60$, age 14 to 19) were administered the YRBS and NPBI-III during the 2012 UNDIA Time out Wacipi Powwow in Grand Forks, ND. Results suggested females were less likely to engage in sexual behaviors that contribute to unintended pregnancy and sexually transmitted diseases including HIV infection than males. Participants identifying themselves as traditional were less likely be inactive and overweight than those who identified themselves as non-traditional. The present study provided insight into gender differences and cultural identification in regards to Northern Plains American Indian adolescent health-risk behaviors. 


\section{CHAPTER I}

\section{INTRODUCTION}

There is an inherent need for individuals to live and survive in their environment. The United States has made a great effort to make the lives of citizens safer and healthier through government mandates, regulations, organizations, and prevention programs. The Centers for Disease Control and Prevention (CDC) has a goal that everyone, especially those at greater risk of health disparities, achieve an optimal lifespan with the highest quality of health at every life stage (Health disparities affecting minorities american indian/alaska natives,2001). Unfortunately many people in the U.S. see themselves as being exposed to more risks than faced by those in the past and believe the situation is

getting worse (Slovic,1999). Of particular concern are the risks faced by American Indian (AI) adolescents living in the United States.

As of 2010 the estimated population of American Indians and Alaskan Natives (AI/AN) was 0.9 percent of the total U.S. population consisting of approximately 3 million people (Indian affairs FAQs, 2012). Those who endorsed being AI/AN in combination to another race was approximately 2 million people (Humes, Jones, Ramirez, 2011). AI adolescents, those younger than 18, constitute roughly $33 \%$ of the Indian population (Jones, S.E., Anderson, K., Lowry, R., Conner, H, 2011a; Sarche \& 
Spicer, 2008). Given the high representation of AI adolescent's research into issues effecting this demographic is important. Research examining the interplay between health risk behaviors and protective factors related to participation in cultural practices is limited (Gray \& Winterowd, 2002; LaFromboise, Hoyt, Oliver, \& Whitbeck, 2006;

LaFromboise, Albright, \& Harris, 2010; Mmari, K.N., Blum, R.W., Teufel-Shone, N., 2010; Silmere \& Stiffman, 2006).

Research on the relationship between cultural identification and health risk behaviors in AI adolescents is needed to help native communities develop and strengthen effective prevention programs. This study focused on AI adolescents attending the 2012 UNDIA Time out Wacipi Powwow and used assessment's that have been developed for and used with American Indians. The purpose of this study was to determine if gender and cultural identification as measured by the Northern Plains Biculturalism Inventory III (NPBI-III) would effect the overall reported health related risk as measured by the Youth Risk Behavior Survey (YRBS).

Studies on Risk and Protective factors for American Indians

Whitbeck et.al (2009) conducted a study of 459 North American Indian Adolescents 11-13 years of age living in the Midwest of the U.S. and Canada. Their study found that traditional spirituality and practices along with cultural identity may be protective factors for American Indian youth. Spirituality and social contexts are associated with perceived life chances and aspirations among American Indian adolescents (Whitbeck ,Walls, Johnson, Morrisseau, McDougall,2009). A study by Lafromboise et al. (2006) found that American Indian youth who participate in traditional 
practices have greater academic success, social skills, and higher self-esteem than nonparticipating peers.

Studies by Gray and Winterowd (2002) as well as Rutman et al. (2008) have addressed risk factors associated with American Indians living in urban or nonreservation areas. Gray \& Winterowd (2002) found boys were more likely than girls to experience health problems, substance abuse problems, and injury risks. The importance in developing support networks and interventions for urban and non-reservation American Indian adolescents needs to be addressed in order to reduce risk (Gray \& Winterowd, 2002; Rutman, Park, Castor, Taualii, \& Forquera, 2008).

Silmere and Stiffman (2006) conducted a study on environmental and cultural factors related to healthy functioning in American Indian Adolescents $(\mathrm{n}=401)$. They found that strengthening families and creating safer communities may enhance successful functioning in native adolescents. Interestingly Silmere and Stiffman found the role of participating in traditional American Indian activities may not be an appropriate intervention method (Silmere \& Stiffman, 2006). This study found that adolescents who participated in traditional activities were associated with less successful functioning.

Research to date has examined many different areas of risk and protective factors among American Indian adolescents. There are several factors that limit current research. Often findings from studies can only be generalized to specific tribes, regions, and location (i.e. reservation or non-reservation) and the number of studies with AI populations are limited (Sarche \& Spicer, 2008). Assessment's used to study risk and cultural practices of American Indians are wide and varied. Many studies have used risk 
assessments that were developed for American Indians living in a different region or have used assessments not made for use with American Indian adolescents. Research studies with AI adolescents have also been subject to small samples representing single tribes or small samples in national surveys (Pavkov, Travis, Fox, King, \& Cross, 2010).

In order to conduct sound reliable research with American Indian adolescents several factors should be addressed. These factors include the increased oversampling of American Indian youth in order to gain a better estimate of risk factors, studies exploring the cultural context of the indicators being measured, and development of culturally effective programs (Pavkov et al., 2010). Tribes and health prevention programs would also benefit from assessments that are nationally used and recognized given that most funding for American Indian services and research comes from the federal government.

\section{Risk Assessment}

Risk assessment refers to assessment tools used when threats to human health, safety, or the environment are of concern (Anderson, Chirba-Martin, Elliott,Farina, Gellhorn, Graham, et al., 2000; Slovic,1999). The data gathered from risk assessments provide valuable information about the risk adolescents are experiencing in their day to day lives. Risk assessment data helps inform the public about the efficacy of different prevention programs which drives professional development and research (Foti, Balaji, \& Shanklin, 2011). The use of assessments that are common in government organized national surveys help researchers and American Indian tribes, people and agencies gain funding for future programs. 
The Center for Disease Control and Prevention (CDC) developed the Youth Risk Behavior Surveillance System (YRBSS) in order to determine health-risk behaviors which contribute to the leading causes of death, social problems, and disability among adolescents in the United States (Brener, N.D., Kann, L., Kinchen, S.A., Grunbaum, J.A., Whalen, L., Eaton, D., Hawkins, J., Ross, J.G., 2004). The YRBSS was first conducted in 1990 and has been conducted every two years since 1991 (Foti et al., 2011).

In 1991 and 1999 the YRBS underwent psychometrics to test the validity and reliability of the assessment (Brener, Kann, Kinchen,Grunbaum, Whalen, Eaton,Hawkins, Ross, 2004; Brener,Kann, McManus, Kinchen, Sundberg, Ross, 2002). The YRBS underwent two studies examining the test-retest reliability in 1992 and 2000 (Brener et al., 2004). The 1992 study found that 7th grade students had lower test-retest reliability than those in higher grades which indicated that the YRBS is better suited for students in eighth grade or higher (Brener et al.,2004). During the test-retest reliability study of 2000 certain items were revised or deleted from the questionnaire due to different prevalence estimates found during the test-retest indicating that the reliability of these items were questionable (Brener et al.,2004). The YRBSS has been determined to be a reliable measure of health risk behaviors among adolescents especially for drug use and sexual activity ( Brener, Kann, McManus, Kinchen, Sundberg, Ross, 2002).

The validity of the YRBS was reviewed in 2003 examining the existing empirical literature assessing situational and cognitive factors that may affect the validity of selfreporting on the YRBS (Brener et al.,2004). The review found that while self-reporting on the YRBS are affected by situational and cognitive factors these factors do not affect the validity of self-reported behaviors equally (Brener et al., 2004). Understanding which 
self-reported behaviors are more likely to be affected by situational and cognitive factors (i.e. sexual behaviors, tobacco use) is important when considering the validity of participant responses.

The YRBS has been used by the CDC to analyze and track health-risk behaviors of American high school students. Data from the YRBS has documented the prevalence and scope of youth health-risk behaviors. The YRBS been used to develop policies and programs, monitor programs already in place, support health-related legislation, create awareness, gain funding for health-related programs, and prevent health risk behaviors among adolescents (Brener et al., 2002).

The YRBS assess risk factors such as unintentional injuries and violence, tobacco use, alcohol and other drug use, physical activity, sexual behaviors contributing to unplanned pregnancy and sexually transmitted disease, and unhealthy dietary behaviors. The assessment does not focus on the determinants of health-risk behaviors (Brener et al., 2004; Brener et al., 2002). Thus the unique role of cultural identity among AI adolescents cannot be assessed through the use of the YRBS.

\section{Adolescent Mortality and Health-Risk Behaviors}

The Centers for Disease Control (CDC) from 1999-2006 reported an average of 16,375 deaths per year occurred for teenagers between 12-19 years of age (Minino, 2010). The mortality of adolescents is a public health concern given that the majority of deaths among 12-19 year olds are caused by injuries such as homicide, suicide, and accidents (Minino, 2010). Health risk behaviors such as unprotected sexual intercourse, cigarette smoking, alcohol consumption, and weapon-carrying contribute to the 
morbidity, mortality, and social problems among adolescents (Brener, Billy, Grady,2003). Health risk behaviors mentally and physically affect the present and future health of adolescents.

The excessive consumption of alcohol by American adolescents is a major health concern. American adolescents tend to binge drink, drive while intoxicated, and ride with a driver who is intoxicated, and are less likely to wear a seatbelt (Siegel, Naimi, Cremeens, Nelson, 2011). The consumption of alcohol contributed to $32 \%$ of U.S. traffic fatalities in 2008 (National Center for Health Statistcs. Health, United States 2010: With Special Feature on Death and Dying, 2011). Adolescents who consume alcohol also face consequences which include: difficulty in school, social issues, physical and sexual assault, suicide, alcohol poisoning, and alterations in brain development (The scope of the problem.2004; Cavazos-Rehg, Krauss, Spitznagel, Schootman, \& L.B., 2011). Studies have shown that adolescents who begin drinking early in life are at increased risk of developing an alcohol disorder later in life (The scope of the problem, 2004).

Unprotected sexual intercourse among adolescents is an area of great concern given the possibility of sexually transmitted diseases, unintended pregnancies, and possibility of physical and sexual assault (Cavazos-Rehg, Krauss, Spitznagel, Schootman, \& L.B., 2011). From 1991-2001 the use of condoms during intercourse increased as did the use of alcohol and other drugs (Trends in sexual risk behaviors among high school students --- united states, 1991--2001). The use of alcohol and other drugs during or before intercourse may inhibit impulse control and impair cognitive functioning which could result in risky sexual behaviors. 
Adolescents who use tobacco products are at higher risk for developing cancer and other health related problems like asthma (Nasim, Blank, Berry, \& Eissenberg, 2011). In 2009 approximately $23.9 \%$ of high school adolescents reported using some kind of tobacco product (Centers for Disease Control and Prevention (CDC), 2010). Tobacco use during adolescents not only has a negative health impact but is an addictive substance that is hard to quite the longer it is used.

American Indian Adolescent Mortality and Health-Risk Behaviors

The American Indian/ Alaskan Native adolescent population has an injury and unintentional injury death rate higher than any other ethnic population of children 10-19 years old (Bernard et al. 2007). American Indian adolescents represent a group vulnerable to preventable health issues which may evolve into health pathology in later adulthood (Curtis, Waters, \& Brindis, 2011). The data available from national surveys providing information on health risk behaviors for AI adolescents is hard to find given the sample size for this population is small (Hawkins, Cummins, \& Marlatt, 2004). Studies that are available indicate major health disparities for American Indian/ Alaskan Natives.

Chronic diseases, Infant Mortality, Sexually Transmitted Diseases, injuries, and drug and alcohol abuse are common among many AI/AN communities (The scope of the problem 2004; Gray \& Winterowd, 2002; Hawkins et al., 2004). Overweight and obesity rates in $\mathrm{AI}$ adolescents are higher than those in all U.S. races combined (Newman, Sontang, \& Salvato, 2006). Fewer options for fresh produce and whole foods in rural areas represent a dietary risk for A.I. adolescents. High rates of diabetes in AI population make overweight and obesity rates among AI adolescents a major health concern. 
According to the CDC injuries account for $75 \%$ of all deaths among AI/AN less than 19 years of age (Injury mortality among american indian and alaska native children and youth united states1989-1998,2003).The death rate of AI's 19 years old or younger is two- times higher than other racial/ethnic populations in the United States (Injury mortality,2003). Motor vehicle accidents, suicide, homicide, drowning, and fires were the leading causes of death among AI/AN youth.

A major contributor to injury-mortality among American Indian adolescents is alcohol. Substance abuse has continued to damage Native communities and is cited as one of the most critical health concerns facing AI /AN communities (Hawkins, Cummins, \& Marlatt, 2004). American Indian youth have an estimated $75 \%$ of suicides, $80 \%$ of homicides and the highest rate of motor-vehicle- death rates due to alcohol (Injury mortality,2003). It is evident that programs focusing on alcohol prevention are needed in communities dealing with high rates of adolescent alcohol abuse.

The rate of injury-mortality among AI/AN youth is not the same for every tribe or IHS service area. The Aberdeen and Billings IHS areas had motor-vehicle mortality rates 3 times the national average and suicide rates higher than the $95^{\text {th }}$ percentile compared to all state rates (Injury mortality, 2003). The high rates of injury-mortality among AI/AN youth may overshadow the fact that this population experiences trauma related to the same incidents (motor-vehicle accidents, suicide, homicide) as either witnesses or survivors (Sarche \& Spicer, 2008). Unfortunately the reported injury-mortality for AI's is only an estimate. The true rate of American Indian injury-mortality is not known. Information regarding injury-mortality is hindered by inaccurate records and misclassification of race/ethnicity on state death certificates (Injury mortality, 2003) 
Funding for AI/AN prevention programs usually comes from the federal government by way of Indian Health Service (IHS), Bureau of Indian Affairs (BIA), and grants. Approximately one-quarter of the AI population lives in poverty (Sarche \& Spicer, 2008). Poverty, limited access to health care, and unemployment are all factors common to many Native communities and are associated with poor health outcomes (Jones et al. 2011). Most preventative services available in these communities are underfunded, subject to termination, and available for a limited amount of time. Research is needed to provide a clearer understanding of the health risk behaviors American Indian adolescents face in order to maintain funding and support for prevention programs. Once the scope of the problem can be established community intervention programs can be developed and sustained meeting individual tribal needs and strengthening the community.

American Indians of the Northern Plains: beliefs, worldviews, attitudes, and acculturation

American Indian youth live in a society which demands the constant adjustment of their culture to that of non-Indian white American culture (LaFromboise et al., 2006). American Indian youth have received an abundance of negative attention due to various health-risk behaviors that occur within reservation communities (Silmere \& Stiffman, 2006). In order to understand the present day health-risk behaviors occurring in reservation communities it is important to consider the historical loss and trauma across American Indian generations.

It has been estimated that prior to European contact 500 years ago, the indigenous population may have been as high as 18 million and consisted of at least 600 different 
tribes (Graham, 2002; Sarche \& Spicer, 2008). From 1500-1900 the death rate for the indigenous people of North America was higher than the birth rate (Graham, 2002). American Indians have endured colonization, forced relocation, boarding schools, disease epidemics, genocide, and cultural trauma (Graham, 2002)(Bill,1988). The effects of these events are still seen today.

According to Whitbeck et al. (2009) one-fifth to one-third of American Indian adults and one-fifth of children (11-13 years old) reported having daily thoughts pertaining to historical loss. Individuals reported that these thoughts have negative emotional consequences (Whitbeck et al.2009). This is evidence that intergenerational transmission of trauma has occurred (Whitbeck et al. 2009). A reason that historical trauma may be effecting the current generation of American Indian youth is the emphasis on family ties, intrinsic worth, and traditional customs and beliefs within tribal communities (Garrett, 1999).

The discussion of cultural practices with American Indians is a sensitive subject. Often elders and those who know cultural traditions will not discuss the meaning and practice of sacred ceremonies with outsiders. There are two reasons for the nondisclosure of cultural practices.

The first reason is the active discouragement of Native American practices from 1492 until the passing of the American Indian Religious Freedom Act in 1978 (Garroutte et al., 2009). During the early 19th century American Indian ceremonies were forbidden under the "Indian Religious Crimes Code," later codified as the "Rules for Indian Courts" with harsh punishment for participating in traditional ceremonies (i.e. withholding food 
and imprisonment)( Garroutte et al., 2009). Given the severity of punishment most American Indians participated in traditional ceremonies in secret.

The historical discouragement of traditional practices and the need for secrecy when participating in ceremonies lingers on to this day. For many the discouragement of cultural ceremonies may lead many AI unwilling to discuss or disclose use of such plants such as tobacco.

The second reason for the non-disclosure of cultural practices to outsiders is that it is not customary to answer questions. The learning of many ceremonies and practices were taught through experience. In many tribes elders do not tell you everything you want to know but teach you when you need or are ready to know. Asking questions instead of waiting for the answers is considered rude.

\section{Protective Factors and Resilience}

Protective factors can be thought of as those factors that help to foster resilience in youth and initiate a process which decreases the likelihood of negative outcomes (Arrington \& Wilson, 2000). Adolescents who navigate their way through adversity to find culturally meaningful experiences and health resources will have a different understanding of adversity and recognize available behavior options than those who do not (Lee, Kwong, Cheung, C., Ungar, Cheung, M., 2010) . The behavior options considered by youth who have found culturally meaningful experiences and health resources will positively influence their actions (Lee et al.,2010).

Protective factors that are specific to the culture and community context of American Indians are still unknown (Hawkins, Cummins, Marlatt, 2004). According to 
James Clairmont, a Lakota elder, the closest meaning for Lakota to the word resilience is the word resistance (LaFromboise, Hoyt, Oliver, \& Whitbeck, 2006). In Lakota the meaning of the word resistance refers to the resistance of bad thoughts and behaviors and the acceptance of bad situations with a good heart (LaFromboise, Hoyt, Oliver, \& Whitbeck, 2006).

American Indian youth living on reservations are faced with many stressors that require resourcefulness, competence, and flexibility (LaFromboise, Hoyt, Oliver, \& Whitbeck, 2006). For American Indian youth the reservation may present a protective factor not found in urban American Indian communities. The reservation may serve as a protective factor for American Indian youth because it is an area in which spiritual and cultural revival is taking place (LaFromboise, Hoyt, Oliver, \& Whitbeck, 2006).

American Indian traditional culture is likely to be associated with pro-social behaviors because the values that are taught promote a sense of self-esteem and efficacy (Whitbeck, Hoyt, Stubben, \& LaFromboise, 2001). Having a secure ethnic identity can lead to a greater understanding and awareness of intergroup relations, mature intercultural thinking, and higher self-esteem (Phinney, Jacoby, \& Silva, 2007). The practice and commitment of American Indian youth to traditional practices provide meaning that makes the world more comprehensible (Garroutte, Goldberg, Beals, Herrell, \& Manson, 2003).

American Indians of the Northern Plains

In the United States there are currently 566 federally recognized American Indian tribes and Alaskan villages (Indian Affairs FAQ'S, 2012). Each tribe is unique in their 
cultural beliefs and practices. The uniqueness of tribal customs makes it impossible to confidently generalize findings from one tribe to another. Although each tribe is unique there are similarities between tribes living in the same region.

There are 12 cultural areas for North and Middle America: Northeast, Southeast, Southwest, Great Plains, Great Basin, Plateau, Northwest coast, California, Mesoamerica, Subarctic, and Circum-Caribbean (American Indian Culture Areas, 2012). Tribes living within the same region share a significant number of cultural traits and delineate cultural areas (American Indian Culture Areas, 2012). Generalizations of research studies become less accurate when tribes are compared from different regions. The assessment and understanding of tribal and regional cultural values is needed in order to assist in academic, emotional, and physical development in American Indian youth (Garrett, 1999).

The Great Plains region stretches from the Mississippi River Valley to the Rocky Mountains and from Manitoba to Texas (American Indian Culture Areas, 2012). American Indians of the Northern Plains refer to U.S.A. tribes in Iowa, Minnesota, South Dakota, Wisconsin, Montana, Wyoming, and North Dakota (American Indian Culture Areas, 2012). Tribes within this region differ from one another in language, creation stories, cultural practices, and history and are more similar the closer they are in proximity. Thus tribes in southern North Dakota are more similar to those in northern South Dakota and are less similar to those living in western Montana. 


\section{Hypothesis}

1) American Indian adolescents identifying as traditional, as measured by the NPBI-III, would have lower health-risk behaviors across all 6 categories of the YRBS than adolescents identifying as non-traditional.

2) Males who identified as being traditional would have more risk when compared to females who identified as being traditional.

3) Males and females who identified as traditional would have less health-risk behaviors than non-traditional individuals of the same gender. 


\section{CHAPTER II}

\section{METHODS}

\section{Participants}

Participants were AI adolescents attending the $42^{\text {nd }} 2012$ UNDIA time- out Wacipi powwow at the University of North Dakota. There were a total of 60 participants (male $=30$, female $=30$ ) between the ages of 14-19 who participated in this study. The amount of participants needed was calculated using the Gpower 3.1.3 program using a medium effect size for the Univariate Analysis of Variance.

Participants were not required to be currently enrolled in school but must be within the ages of 14 to 19 years of age given that the YRBS was originally developed for high school aged students (A guide to conducting your own youth risk behavior survey, 2009). All participants were from the Northern Plains region. Eligibility for participation required parental/caregiver approval which was obtained before survey administration. The voluntary participation of each student was also obtained before conducting the study.

\section{Measures}

The following measures comprise materials administered to participants. The materials assessed demographic information, informed consent, parental/caregiver permission, cultural practices/ beliefs, and health-risk behaviors. 


\section{Demographic Questionnaire}

Participants received a questionnaire assessing demographic information. The demographic questionnaire was developed by the lead investigator to explore eligibility for study participation. Demographic questionnaires were coded and matched to questionnaire packets. The questionnaire assessed: age, gender, tribal affiliation, state in which tribe is from, and current residency. Information obtained provided general characteristics of the sample.

\section{Informed Consent}

Parents/caregivers as well as participants received informed consent forms that were signed before participating in the study. Participants were told that their participation in the study was voluntary and they were free to stop the study at any time without consequences.

Participants in the study remained anonymous and all information was kept confidential. Participant's questionnaires were coded and kept in a separate location from informed consent forms in order to prevent any participants association with the study. The informed consent forms were created according to the guidelines of the UND Institutional Review Board (IRB).

\section{Youth Risk Behavior Survey}

Participants completed a survey assessing health risk behaviors across six categories: behaviors that contribute to unintentional harm and violence, tobacco use, alcohol and other drug use, sexual behaviors and sexually transmitted diseases, unhealthy 
dietary behaviors, and physical inactivity. The Youth Risk Behavior Survey (YRBS) is a self-administered 86 item survey used to monitor the prevalence of behavior that influences adolescent health (Data on health and well-being of american indians, alaska natives, and other native americans, data catalog.2006). The YRBS was developed by the Centers for Disease Control and Prevention (CDC) to determine the prevalence, stability, and co-occurrence of youth health-risk behaviors (Brener, N.D., Kann, L., Kinchen, S.A., Grunbaum, J.A., Whalen, L., Eaton, D., Hawkins, J., Ross, J.G., 2004).

Iowa (2007), Montana (2009), North Dakota (2009), South Dakota (2009), Wisconsin (2009), and Wyoming (2009) have all participated in the High School YRBS (Participation history and data quality, 1991-2009 high school.). These states (excluding Minnesota who did not participate in the YRBS) are the states in which Northern Plains American Indian tribes are found. From 1991-2009 there were no tribes from the Northern Plains participating in the high school YRBS (Participation history and data quality, 1991).

Northern Plains Biculturalism Inventory III

Participants completed a survey assessing behaviors related to cultural practices, beliefs, and acculturation. The Northern Plains Biculturalism Inventory III (NPBI-III) is a 25 item self-administered survey used to assess social behaviors related to beliefs, worldviews, attitudes, and acculturation of American Indians of the Northern Plains (Baker, 2009). All questions on the NPBI-III are on a four point likert scale. The NPBIIII contains two subscales. The first subscale measures American Indian cultural 
identification and the second measures European American cultural identification (Baker, 2009).

In 2005 an analysis of construct validity and reliability was conducted and a new scale developed (Baker, 2009). The Northern Plains Biculturalism Inventory -Revised (NPBI-R) was developed following Baker's study which made the NPBI-R more efficient in measuring cultural identification among American Indians living in the Northern Plains(Baker, 2009). In 2011 the NPBI was further revised into the NPBI-III and is currently undergoing psychometric testing.

\section{Procedure}

The Youth Risk Behavior Survey (YRBS) and the Northern Plains Biculturalism Inventory III (NPBI-III) was administered to participants during the $42^{\text {nd }}$ annual UNDIA time-out Wacipi. Informed consent was gathered from all interested participants and parent/guardians. Participants met eligibility requirements as determined from the demographic questionnaire. Each demographic questionnaire was coded to match a specific questionnaire packed. An informative sheet explaining the study and eligibility to participate in the study was provided to interested parties. The lead investigator was available and addressed any questions or concerns prior to and after the study.

Eligible participants were escorted to a private area where they received instructions from a prepared script on how to complete the questionnaires. The participants were informed that participation in the study was voluntary and they may stop at any time without consequence. Participants were given a pencil, coded packet (containing YRBS and NPBI-III questionnaires), extra paper, and sound proof ear plugs. 
Participants marked their answers directly on the YRBS and NPBI-III in pencil.

Participants were given an extra sheet of paper in order to hide their answers and protect their confidentiality. Ear plugs were also provided to reduce surrounding noise.

Completion of the questionnaires took approximately 20 minutes. When completed, participants placed all questionnaires back into the coded envelope. Participants were thanked for their participation in the study and were asked if they had any further questions or concerns. Participants received monetary compensation in the form of $\$ 5.00$ upon the completion of the survey. Results of the study are to be presented at the 43rd annual UNDIA time-out Wacipi in order to share the results from the previous year's powwow.

Records are kept in the Indians into Psychology Doctoral Education office in a secure filing cabinet. Records containing informed consent are separately from the questionnaire packets in order to protect the confidentiality and anonymity of the participants. All records will be kept for a maximum of five years at which time they will be shredded in accordance with UND Institutional Review Board (IRB) guidelines.

\section{Data Analysis}

The study used SPSS 20.0 statistics software to code and analyze data. Descriptive statistics were examined for the entire data set evaluating the characteristics of the sample. Descriptive statistics included frequencies, means, medians, standard deviations, minimums, maximums, range of scores, skewness, kurtosis, missing data, percentages of demographic variables, and percentages of questionnaire variables. 
SPSS 20 was used to analyze the data gathered from the YRBS. SPSS statistic software was able to account for the complex design of the YRBS and point estimates, standard errors, confidence intervals and tests of hypotheses were obtained (Centers for Disease Control and Prevention (CDC), 2009).

Data analyses were conducted testing hypotheses. The first statistical analysis consisted of a Pearson's product-moment correlation (r). The Pearsons (r) determined the directionality and strength of the linear relationship between the NPBI-III, YRBS, and demographic information.

The second analysis was a two-factor Univariate Analysis of Variance (ANOVA). The ANOVA examined the relationship between AI cultural identification and gender on health-risk behaviors. The F ratios, $\mathrm{p}$ values and effect sizes were reported for the two (gender) x two (traditional or non-traditional) x six (unintentional injuries and violence (injuries/violence), tobacco use, alcohol and other drug use (alcohol/drugs), physical activity (weight), sexual behaviors contributing to unplanned pregnancy and sexually transmitted disease (sexual behaviors), and unhealthy dietary behaviors (unhealthy behaviors)) risk behavior factoral design. 


\section{CHAPTER III}

\section{RESULTS}

Descriptive Characteristics of the Sample

The tribal background of the sample was limited to participants from Northern Plains tribes. The specific tribes represented in the sample is known but was not reported in order to protect the confidentiality of the study participants. A total of 60 participants (female $=30$, male $=30$ ) participated in the study. Based on median-split technique (median of 2 for EACI and 3 for AICI) participants were classified as traditional or nontraditional. Participants identifying as traditional or bicultural were classified as traditional, participants identifying as marginal or assimilated were classified as nontraditional. Based upon group identification 55\% $(n=33)$ were classified as being traditional and $45 \%(n=45)$ were classified as being non-traditional. The means and standard deviations were calculated for all of the measures (see Table 1) as well as the demographic questions. 
Table 1. Descriptives and Frequencies for risk categories, cultural identification, and demographic information.

\begin{tabular}{|c|c|c|c|c|}
\hline & $\mathrm{N}$ & Mean & $\mathrm{SD}$ & $\%$ \\
\hline Injuries/Violence & 60 & 34.38 & 4.15 & \\
\hline Tobacco Use & 60 & 18.68 & 6.40 & \\
\hline Alcohol/Drug Use & 60 & 34.05 & 11.94 & \\
\hline Sexual behaviors & 60 & 94.19 & 24.86 & \\
\hline Activity Level & 60 & 18.73 & 7.51 & \\
\hline Dietary Behaviors & 60 & 18.22 & 7.20 & \\
\hline \multicolumn{5}{|l|}{ Cultural Identity } \\
\hline Traditional & 33 & & & 55 \\
\hline Non-traditional & 27 & & & 45 \\
\hline \multicolumn{5}{|l|}{ Age } \\
\hline 14 years of age & 16 & & & 26.7 \\
\hline 15 years of age & 11 & & & 18.3 \\
\hline 16 years of age & 7 & & & 11.7 \\
\hline 17 years of age & 5 & & & 8.3 \\
\hline 18 years of age or older & 21 & & & 35 \\
\hline \multicolumn{5}{|l|}{ Grade } \\
\hline $9^{\text {th }}$ & 15 & & & 25 \\
\hline $10^{\text {th }}$ & 9 & & & 15 \\
\hline $11^{\text {th }}$ & 6 & & & 10 \\
\hline $12^{\text {th }}$ & 5 & & & 8 \\
\hline Ungraded/Other & 25 & & & 41.7 \\
\hline
\end{tabular}




\section{Group Comparisons}

To evaluate Hypothesis 1 a one way analysis of variance (ANOVA) examining the relationship between the six categories of risk (behaviors that contribute to unintentional harm and violence, tobacco use, alcohol and other drug use, sexual behaviors and sexually transmitted diseases, unhealthy dietary behaviors, and physical inactivity) and cultural identification (traditional or non-traditional). There were significant differences between physical inactivity regarding obesity and overweight and cultural identity $[\mathrm{F}(1,30871.476)=5.911, \mathrm{p}<.05]$. There were no significant differences between behaviors that contribute to unintentional harm and violence $[F(1,942.434)=2.303, p>, 05]$, tobacco use $[F(1,2222.168)=.575, p>.05]$, alcohol and other drug use $[F(1,7981.170)=1.956, p>.05]$, sexual behaviors and sexually transmitted diseases $[\mathrm{F}(1,2963.074)=1.129, \mathrm{p}>.05]$, unhealthy dietary behaviors $[\mathrm{F}(1,2995.260)=.037, \mathrm{p}>.05]$ and cultural identity.

To evaluate Hypothesis 2 and 3 a one way analysis of variance (ANOVA) examining the relationship between the six categories of risk behaviors (behaviors that contribute to unintentional harm and violence, tobacco use, alcohol and other drug use, sexual behaviors and sexually transmitted diseases, unhealthy dietary behaviors, and physical inactivity) cultural identification (traditional or non-traditional) and gender. There were significant interactions for sexual risk behaviors and gender $[\mathrm{F}(1,2963.074)=5.621, \mathrm{p}<.05]$ and physical inactivity and gender $[\mathrm{F}(1,30871.476)=5.773$, $\mathrm{p}<.05]$. 
There were no significant differences between behaviors that contribute to unintentional harm and violence $[\mathrm{F}(1,942.434)=.626, \mathrm{p}>.05]$, tobacco use $[\mathrm{F}(1,2222.168)=.920, \mathrm{p}>.05)$, alcohol and other drug use [F1,7981.170)=.237, $\mathrm{p}>.05]$, sexual behaviors and sexually transmitted diseases $[\mathrm{F}(1,2963.074)=.463, \mathrm{p}>.05]$, unhealthy dietary behaviors $[\mathrm{F} 1,2995.260)=.019 . \mathrm{p}>.05]$, physical inactivity $[\mathrm{F}(1,30871.476)=.010, \mathrm{p}>.05]$ cultural identification and gender.

Pearson correlations were calculated to examine the relationship between six categories of health- risk behaviors (behaviors that contribute to unintentional harm and violence, tobacco use, alcohol and other drug use, sexual behaviors that contribute to unintended pregnancy and sexually transmitted diseases including HIV, unhealthy dietary behaviors, and physical inactivity), cultural identification (traditional or non-traditional), participant demographics (age, and gender). Results of the correlations can be found in Table 2.

There were significant correlations between the participants age and tobacco use $[\mathrm{r}$ (.384), $n=60, p .002]$, indicating that as the age of the participant increases so does tobacco use. Age and alcohol/other drug use were also significant [r (.411), $n=60, p .001]$, indicating that as the age of the participant increases so does the use of alcohol/other drugs. Age and sexual behaviors were significant [r (.647), $n=60, p=.000]$, indicating that as the participants get older their sexual behaviors increase. Age and cultural identification were also significant $[\mathrm{r}(.268), \mathrm{n}=60, \mathrm{p}=.039]$, indicating that as participants get older they are more likely to identify as being non-traditional.

Significant correlations were found between gender and sexual behaviors [ $\mathrm{r}$ (.291), $\mathrm{n}=60, \mathrm{p}=.024]$, indicating that males tend to have an increase in sexual behaviors. 
The positive correlation between tobacco use and alcohol/other drug use $[\mathrm{r}(.581), \mathrm{n}=60$, $\mathrm{p}=.000]$ indicates that as tobacco use increases so does the use of alcohol and other drugs. Tobacco use and sexual behaviors also had a significant correlation [r (.542), $\mathrm{n}=60, \mathrm{p}=.000]$. This indicates that as the use of tobacco increases so does sexual behaviors. The final significant correlation found was alcohol/other drug use and sexual behaviors $[\mathrm{r}(.414), \mathrm{n}=60, \mathrm{p}=, 001]$, indicating that as the use of alcohol/other drugs increase so does sexual behaviors.

Table 2. Correlations Between Demographic Information, Health Risk Categories, and Cultural Identity.

\begin{tabular}{|c|c|c|c|c|c|c|c|c|c|}
\hline 1 & 2 & 3 & & 5 & 6 & 7 & 8 & 9 & \\
\hline 1. Age & --- & -.242 & -.077 & $.394 * *$ & $.411 * *$ & $.647 * *$ & .161 & -.048 & $.268^{*}$ \\
\hline 2. Gender & & --- & .166 & .244 & .111 & $.291 *$ & .252 & .142 & -.168 \\
\hline 3. Injuries/ & ence & & --- & .190 & .061 & -.020 & -.124 & .115 & -.223 \\
\hline 4. Tobacco & & & & --- & $.581 * *$ & $.542 * *$ & .050 & .070 & .035 \\
\hline 5. Alcohol/ & & & & & --- & $.414 * *$ & 239 & -.081 & .163 \\
\hline 6. Sexual B & viors & & & & & --- & .003 & .133 & .086 \\
\hline 7. Activity/ & & & & & & & -- & .176 & .253 \\
\hline 8. Dietary I & iviors & & & & & & & --- & .001 \\
\hline 9. Cultural & & & & & & & & & --- \\
\hline
\end{tabular}

$* \mathrm{p}<.05 ; * * \mathrm{p}<.01$

Note. Age=Age of participant, Injuries/Violence=Behaviors that result in unintentional injuries and violence, Alcohol/Drugs=Alcohol and other Drug use, Sexual Behaviors=Sexual behaviors that contribute to unintended pregnancy and sexually transmitted diseases, including HIV infection, Activity/weight= physical inactivity, Dietary Behaviors $=$ Unhealthy dietary behaviors, Cultural Identity $=$ traditional or non-traditional 


\section{CHAPTER IV}

\section{DISCUSSION}

It was hypothesized that Northern Plains American Indian adolescents with higher American Indian (AI) cultural identification would score lower on all areas of the YRBS than adolescents reporting lower AI cultural identification. Gender and cultural identification were also expected to affect health-risk behaviors. Results suggest participants identifying as traditional had less physical inactivity than those identifying as non-traditional. Findings suggest that cultural identity is related to physical activity and body weight. As found in previous studies, physical activity and body weight may be related to cultural identity through individual, social, and environmental factors (Gray \& Winterowd, 2002; Jones, S.E., Anderson, K., Lowry, R., Conner, H, 2011; Newman, Sontag, \& and Salvato, 2006).

Individual factors increasing or decreasing the likelihood of engaging in a given behavior included self-efficacy and perceived body image (Stevens et al., 1999). Selfefficacy (confidence in one's ability) for physical activity, exercise intentions, and specific perceptions of barriers to activity are strongly related to activity in adolescents (Phinney, Jacoby, \& and Silva, 2007). Northern Plains AI adolescents identifying as traditional often participate in physically active ceremonies and celebrations (i.e. powwow and sundance). To participate in a traditional ceremony the individual must undergo 
strenuous mental and physical preparation and be committed to completing the ceremony. Preparing to participate in traditional activity re-enforces the commitment to remain physically active and can bolster self-esteem once completed.

A study by Lafromboise et al. (2006) found that American Indian youth who participate in traditional practices have higher self-esteem than non-participating peers. Although more research is needed it may be that AI adolescents identifying as traditional and participating in traditional practices have less health risk associated with physical activity and obesity due to higher self-esteem than those who are non-traditional. As the current study indicates, cultural identity is related to physical activity research is needed to examine cultural identity and self-esteem's relationship to physical activity.

A study by Silmere and Stiffman (2006) found that participating in traditional American Indian activities may not be an appropriate intervention method. Results from the current study indicate that AI adolescents identifying as traditional and who participate in traditional ceremonies have lower dietary health risk than non-traditional AI participants. More research is needed in order to determine how cultural identity influences health-risk behavior.

Gender and cultural identification was also expected to influence health-risk behaviors. There was no significant interaction for gender and cultural identification on health-risk behaviors. Results suggest that gender is related to sexual behaviors and sexually transmitted diseases including HIV. AI adolescent males in this study had an increase in sexual risk behaviors compared to female respondents. 
Contrary to the hypothesis participants identifying as traditional did not have lower health risk for behaviors that contribute to unintentional harm and violence, tobacco use, alcohol and other drug use, sexual behaviors that contribute to unintended pregnancy and sexually transmitted diseases including HIV, and unhealthy dietary behaviors. Trends in data indicate that AI adolescents identifying as traditional tended to have lower risk behaviors in tobacco use, alcohol/other drug use, unhealthy dietary behaviors, and sexual behaviors. Further research is needed in cultural identity and health risk behaviors.

\section{Limitations of the Current Study}

Limitations of this study include the use of self-report measures. Participants may not accurately report current health risk behaviors or cultural identity. Although participants were informed that their information would remain confidential and anonymous some questions regarding health risk behavior and cultural identity may have been difficult to endorse. Response bias may have occurred due to the personal questions being asked regarding health risk behaviors and participation in traditional ceremonies. Self-report measures also limit responses available to participants which may not be an accurate reflection of their behaviors and cultural identity.

Findings of this study should be interpreted with caution for a couple of reasons. Participants in this study were Northern Plains AI adolescents between the ages of 14-19 and are representative to this sample. Due to differences between tribal regions generalizations to other tribes should be done with caution. The median split technique was used in order to categorize participants as traditional and non-traditional. The median split technique is limited in that power is decreased. Finally participants in this study 
were not required to be enrolled in High School. Caution should be taken when generalizing to in school populations.

Findings suggest that traditional activities may be an appropriate intervention method when helping Northern Plains AI adolescents become more physically active and healthy. The finding that cultural identity shares a relationship with physical activity was intriguing and needs further. Research with Northern Plains AI adolescents promotes understanding that may help this at risk demographic live longer healthier lives through programs advocating traditional activities. 
APPENDICES 


\section{Appendix A}

\section{Researcher Script:}

Good (morning/afternoon). This study is seeking to provide information about behaviors that increase the risk of health problems now or in the future as well as protective factors against health risk.

I'd like to thank you for participating. Participating in this survey is voluntary and you may quit at any time without penalty. The answers you give are very important. I ask that you read each question carefully and answer it based on what you really know or do.

I would like to emphasize that this is not a test. The information gathered from this study will be used in order to develop better health education programs, provide information unique to your age group and culture, and can help educators, health officials, parents, and tribal communities find out which behaviors adolescents like you are engaging in. These behaviors may include sexual behaviors that may result in unintended pregnancies and sexually transmitted diseases, including AIDS; tobacco, alcohol, and other drug use; lack of physical activity; poor nutritional habits, behaviors that may lead to injuries, your cultural practices, beliefs, worldviews, and acculturation.

Throughout the entire survey process, I will maintain procedures to protect your privacy and allow for your anonymous participation. Please do not write your name on any of the questionnaires. Your answers are private. Results of this survey will never be reported using your name or any other identifying information.

\section{Distribute Questionnaire Packets. Ask Participants if they have any questions or concerns.}

Please be sure to answer every question. When you are finished, look over your questionnaires to make sure that you haven't skipped any items. Once you have finished both questionnaires, please place them into the envelope and return them to me.

Thank you for your help and your time. 
Appendix B

\section{WE CARE ABOUT YOU AND YOUR FAMILY}

It is common for people to have uncomfortable thoughts or feelings when talking about some of the issues in this survey. Your reactions may be mild or intense.

During or after the questions you or your loved ones may like to talk with someone. Area resources are listed below. We would be happy to help you contact any of these resources if you wish. We are firmly committed to our policy of confidentiality, so, if you decide to seek help for yourself or your family, your decision would be kept confidential.

\section{RESOURCES}

\begin{tabular}{|c|c|c|c|c|}
\hline Type & Location & Program & Phone & $\begin{array}{l}\text { Contact } \\
\text { Persons }\end{array}$ \\
\hline \multicolumn{5}{|c|}{ North Dakota Facilities } \\
\hline ALOD & Belcourt & $\begin{array}{l}\text { Turtle Mountain } \\
\text { Counseling/Rehab Ctr. }\end{array}$ & $(701) 477-3121$ & Peter Azure \\
\hline ALOD & Bismarck & $\begin{array}{l}\text { United Tribes Educational Tech } \\
\text { Center }\end{array}$ & $\begin{array}{l}\text { (701)255-3285 } \\
\text { Ext. } 1210\end{array}$ & Russell Gillette \\
\hline ND & Bismarck & $\begin{array}{l}\text { West Central Human Service } \\
\text { Center }\end{array}$ & $701-328-8888$ & \\
\hline ND & Dickenson & Badlands Human Service Center & $701-227-7515$ & \\
\hline ND & Devil's Lake & $\begin{array}{l}\text { Lake Region Human Service } \\
\text { Center }\end{array}$ & $701-665-2200$ & \\
\hline ND & Fargo & $\begin{array}{l}\text { South East Human Service } \\
\text { Center }\end{array}$ & $\begin{array}{l}701-298-4500 \\
888-342-4900\end{array}$ & \\
\hline ALOD & Fort Totten & $\begin{array}{l}\text { Spirit Lake Nation Recover \& } \\
\text { Wellness Center -- Residential }\end{array}$ & $(701) 766-4285$ & $\begin{array}{l}\text { Evelyn Cavanaugh } \\
\text { Wicapi } \\
\text { Tawaciahehomni } \\
\text { (?) }\end{array}$ \\
\hline ALOD & Fort Yates & $\begin{array}{l}\text { Comp. Chemical Prevention } \\
\text { Program }\end{array}$ & $(701) 854-7219$ & Duane Silk \\
\hline ND & Grand Forks & Northeast Human Service Center & $701-795-3000$ & \\
\hline ND & Jamestown & $\begin{array}{l}\text { South Central Human Service } \\
\text { Center }\end{array}$ & $701-253-6300$ & \\
\hline ND & Minot & $\begin{array}{l}\text { North Central Human Service } \\
\text { Center }\end{array}$ & $\begin{array}{l}701-857-8500 \\
888-470-6968\end{array}$ & \\
\hline ALOD & New Town & Circle of Life & (701)627-4700 & Belinda Beston \\
\hline ALOD & Trenton & $\begin{array}{l}\text { Native American Resource } \\
\text { Center }\end{array}$ & (701)774-9876 & Joe McGillis \\
\hline ND & Williston & Northwest Human Service Center & $\begin{array}{c}\text { 701-774-4600 } \\
\text { C: } 701-572- \\
9111 \\
800-231-7724\end{array}$ & \\
\hline \multicolumn{5}{|c|}{ South Dakota Facilities } \\
\hline ALOD & Aberdeen & $\begin{array}{l}\text { Aberdeen Area IHS- } \\
\text { Alcohol/Substance Abuse }\end{array}$ & (605)226-7553 & George Buffalo \\
\hline
\end{tabular}




\begin{tabular}{|c|c|c|c|c|}
\hline & & Program & & \\
\hline ALOD & $\begin{array}{l}\text { Agency } \\
\text { Village }\end{array}$ & Dakota Pride Center & (605)698-3917 & Richard Bird \\
\hline ALOD & Eagle Butte & Four Bands Healing Center & $\begin{array}{l}(605) 964-8182 \\
(605) 964-8183\end{array}$ & $\begin{array}{l}\text { Danielle Rose } \\
\text { Leonard Ganados? }\end{array}$ \\
\hline ALOD & Flandreau & $\begin{array}{l}\text { Flandreau Santee Sioux Tribal } \\
\text { Counseling Center }\end{array}$ & (605)997-3844 & Pat Hill \\
\hline ALOD & $\begin{array}{l}\text { Fort } \\
\text { Thompson }\end{array}$ & Swift Horse Lodge & (605)245-2245 & $\begin{array}{l}\text { Fee Moran } \\
\text { Art Surrounded (?) }\end{array}$ \\
\hline ALOD & Hot Springs & $\begin{array}{l}\text { VA Hospital } \\
\text { Substance Abuse Program } \\
500 \text { N. Fifth St. }\end{array}$ & $\begin{array}{l}\text { 605-745-2000 } \\
\text { Ext. } 2611\end{array}$ & $\begin{array}{l}\text { Toby Kitzman, } \\
\text { Addiction Therapist }\end{array}$ \\
\hline ALOD & Kyle & Anpetu Luta Otipi- Residential & $(605) 455-2331$ & $\begin{array}{l}\text { Terry Blue/White } \\
\text { Eyes }\end{array}$ \\
\hline $\mathrm{MH}$ & Kyle & $\begin{array}{l}\text { Indian Health Services } \\
\text { Mental Health Clinic }\end{array}$ & $\begin{array}{l}605-455-2451 \\
\text { ext. } 236 \& 235\end{array}$ & $\begin{array}{l}\text { Francis Montileaux } \\
\text { Art Brown }\end{array}$ \\
\hline ALOD & Lower Brule & Lower Brule Counseling Service & (605)472-5584 & Greg Miller \\
\hline ALOD & Lake Andes & Canku Teca Treatment Center & $(605) 487-7841$ & Ron Sully \\
\hline ALOD & Mission & Little Hoop Lodge—Residential & $(605) 856-2342$ & $\begin{array}{l}\text { Marcida Eagle } \\
\text { Bear }\end{array}$ \\
\hline Youth & Mobridge & $\begin{array}{l}\text { Aberdeen Area IHS- Aberdeen } \\
\text { Area Youth Regional Treatment } \\
\text { Center }\end{array}$ & $(605) 845-7181$ & Tom Eagle Staff \\
\hline ALOD & Pine Ridge & Project Recovery & $(605) 867-5332$ & $\begin{array}{l}\text { Terry Blue/White } \\
\text { Eyes }\end{array}$ \\
\hline $\mathrm{MH}$ & Pine Ridge & $\begin{array}{l}\text { Indian Health Services } \\
\text { Mental Health Clinic }\end{array}$ & $605-867-5138$ & $\begin{array}{l}\text { Charlie Stewart } \\
\text { Dr. Trudy Yukel }\end{array}$ \\
\hline ALOD & Rapid City & $\begin{array}{l}\text { Substance Abuse Healing } \\
\text { Program- Residential }\end{array}$ & (605)342-8925 & $\begin{array}{l}\text { Nanette Twiss } \\
\text { Harriet Brings (?) }\end{array}$ \\
\hline COMB & Rapid City & $\begin{array}{l}\text { Veteran's Center } \\
610 \text { Kansas City St. }\end{array}$ & $605-348-0077$ & $\begin{array}{l}\text { Gary Johnson } \\
\text { Counselor }\end{array}$ \\
\hline $\mathrm{MH}$ & Sturgis & $\begin{array}{l}\text { VA Hospital } \\
\text { Psychology Department } \\
\text { Ft. Meade VAMC }\end{array}$ & $\begin{array}{l}\text { 605-347-2511 } \\
\text { Ext.394 }\end{array}$ & $\begin{array}{l}\text { Dr. Fellner } \\
\text { Dr. Elia } \\
\text { Dr. Clearing Sky }\end{array}$ \\
\hline & & & & \\
\hline
\end{tabular}

\section{TOLL FREE NUMBERS}

HELPLine.

National Suicide Prevention Talkline 800-273TALK 800-273-8255

National Suicide Hotline 800-SUICIDE 800-662-HELP

Alcohol Abuse and Crisis Intervention $800-662-4357$

Alcohol and Drug Abuse Helpline and Treatment 800-234-0246 Alcohol Hotline Support \& Information $800-234-0420$ 800-331-2900 


\section{References}

2004 surgeon generals report- the health consequences of smoking executive summary. Retrieved 2/16/2012, 2012, from http://www.cdc.gov/tobacco/data_statistics/sgr/2004/pdfs/executivesummary.pdf

Baker, L. I. (2009). Convergent and discriminant validity of biculturalism and depression among northern plains american indians. ProQuest Information \& Learning). Dissertation Abstracts International: Section B: The Sciences and Engineering, 69(12-) Retrieved from http://ezproxy.library.und.edu/login?url=http://search.ebscohost.com/login.aspx?direct=tr $\underline{\text { ue } \& d b=p s y h \& A N=2009-99120-138 \& \text { site=ehost-live \&scope=site }}(2009-99120-138)$.

Brener, N.D., Kann, L., Kinchen, S.A., Grunbaum, J.A., Whalen, L., Eaton, D., Hawkins, J., Ross, J.G. (2004). Methodology of the youth risk behavior surveillance system. (Morbidity and Mortality Weekly Report No. vol.53/RR-12). Washington, DC: National Center for Chronic Disease Prevention and Health Promotion.

Cavazos-Rehg, P. A., Krauss, M. J., Spitznagel, E. L., Schootman, M., Cottler, \& L.B., B., L.J. (2011). Number of sexual partners and associations with initiation and intensity of substance use. AIDS Behavior, 15, 869. doi: 10.1007/s10461-010-9669-0 
Centers for Disease Control and Prevention (CDC). (2009). United states high school survey data users manual. ().Centers for Disease Control and Prevention. doi: www.cdc.gov/HealthyYouth/YRBS/pdf/national_usermanual_yrbs.pdf

Centers for Disease Control and Prevention (CDC). (2010). Tobacco use among middle and high school students --- united states, 2000-2009. MMWR.Morbidity and Mortality Weekly Report, 59(33), 1063-1068.

Chewning, B., Douglas, J., Kokatailo, K. K., LaCourt, J., St. Clair, D., \& and Wilson, D. (2001). Protective factors associated with american indian adolescents' safer sexual patterns. Maternal and Child Health Journal, 5(4), 273.

Data on health and well-being of american indians, alaska natives, and other native americans, data catalog. (2006). Retrieved 09/7/2011, 2011, from http://aspe.hhs.gov/hsp/06/catalog-ai-an-na/YRBSS.htm

Garroutte, E. M., Goldberg, J., Beals, J., Herrell, R., \& Manson, S. M. (2003). Spirituality and attempted suicide among american indians. Social Science \& Medicine, 56(7), 15711579. doi: 10.1016/S0277-9536(02)00157-0

Gray, J. S., \& Winterowd, C. L. (2002). Health risks in american indian adolescents: A descriptive study of a rural, non-reservation sample. Journal of Pediatric Psychology, 27(8), 717-725. doi: 10.1093/jpepsy/27.8.717

A guide to conducting your own youth risk behavior survey (2009). doi: http://www.cdc.gov/yrbs 
Hawkins, E. H., Cummins, L. H., \& Marlatt, G. A. (2004). Preventing substance abuse in american indian and alaska native youth: Promising strategies for healthier communities. Psychological Bulletin, 130(2), 304-323. doi: 10.1037/0033-2909.130.2.304

Health disparities affecting minorities american indian/alaska natives (2001). (http://www.cdc.gov/omhd/Brochures/PDFs/1PAIAN.pdf ed.) Centers for Disease Control and Prevention.

Indian affairs | FAQs. (2/9/2012). Retrieved 2/9/2012, 2012, from http://www.bia.gov/FAQs/index.htm

Injury mortality among american indian and alaska native children and youth united states, 1989-1998 (2003).

Jones, S.E., Anderson, K., Lowry, R., Conner, H. (2011a). Peer reviewed: Risks to health among american indian/alaska native high school students in the united states. Preventing Chronic Disease Public Health Research, Practice, and Policy, 2012(2/10/2012), 1. doi: www.cdc.gov/pcd/issues/2011/jul/10_0193.htm

Jones, S.E., Anderson, K., Lowry, R., Conner, H. (2011b). Risks to health among american indian/alaskan native high school students in the united states. Preventing Chronic Disease Public Health Research, Practice, and Policy, 4(A76)

Kaufman, C. E., Desserich, J., Big Crow, C. K., Holy Rock, B., Keane, E., \& and Mitchell, C. M. (2007a). Culture, context, and sexual risk among northern plains american indian youth. Social Science \& Medicine, 64, 2152. 
Kaufman, C. E., Desserich, J., Crow, C. K. B., Rock, B. H., Keane, E., \& Mitchell, C. M. (2007b). Culture, context, and sexual risk among northern plains american indian youth. Social Science \& Medicine, 64(10), 2152-2164. doi: 10.1016/j.socscimed.2007.02.003

LaFromboise, T. D., Albright, K., \& Harris, A. (2010). Patterns of hopelessness among american indian adolescents: Relationships by levels of acculturation and residence. Cultural Diversity and Ethnic Minority Psychology, 16(1), 68-76. doi: 10.1037/a0016181

LaFromboise, T. D., Hoyt, D. R., Oliver, L., \& Whitbeck, L. B. (2006). Family, community, and school influences on resilience among american indian adolescents in the upper midwest. Journal of Community Psychology, 34(2), 193-209. doi:

10.1002/jcop. 20090

Mmari, K.N., Blum, R.W., Teufel-Shone, N. (2010). What increases risk and protection for delinquent behaviors among american indian youth.41(3), 382 .

Nasim, A., Blank, M., Berry, B., \& Eissenberg, T. (2011). Cigar use misreporting among youth: Data from the 2009 youth tobacco survey, virginia. Preventing Chronic Disease, doi: $10.5888 /$ pcd9.110084

National Center for Health Statistcs. Health, United States 2010: With Special Feature on Death and Dying. (2011). (). Washington, DC 20402: U.S. Government Printing Office.

Newman, D. L., Sontag, L. M., \& and Salvato, R. (2006). Psychological aspects of body mass and body image among rural american indian adolescents. Journal of Youth and Adolescence, 35(2), 281. 
Participation history and data quality, 1991-2009 high school. Retrieved 9/13/2011, 2011, from htpp://www.cdc.gov/healthyyouth/yrbs/history-states.htm

Pavkov, T. W., Travis, L., Fox, K. A., King, C. B., \& Cross, T. L. (2010). Tribal youth victimization and delinquency: Analysis of youth risk behavior surveillance survey data. Cultural Diversity and Ethnic Minority Psychology, 16(2), 123-134. doi:

10.1037/a0018664

Phinney, J. S., Jacoby, B., \& and Silva, C. (2007). Positive intergroup attitudes: The role of ethnic identity. International Journal of Behavioral Development, 31(5), 478.

Sarche, M., \& Spicer, P. (2008). Poverty and health disparities for american indian and alaska native children: Current knowledge and future prospects. Annals of the New York Academy of Sciences, 1136, 126-136. doi: 10.1196/annals.1425.017

The scope of the problem. (2004). Alcohol Research \& Health, 28(3), 111-120. Retrieved from

http://ezproxy.library.und.edu/login?url=http://search.ebscohost.com/login.aspx?direct=tr $\underline{\mathrm{ue} \& \mathrm{db}=\mathrm{psyh} \& \mathrm{AN}=2006-01495-002 \& \text { site}=\text { ehost-live } \& \text { scope }=\text { site }}$

Silmere, H., \& Stiffman, A. R. (2006). Factors associated with successful functioning in american indian youths. American Indian and Alaska Native Mental Health Research, 13(3), 23-47. Retrieved from http://ezproxy.library.und.edu/login?url=http://search.ebscohost.com/login.aspx?direct=tr $\underline{\mathrm{ue} \& \mathrm{db}=\mathrm{psyh} \& \mathrm{AN}=2006-21795-002 \& \text { site}=\text { ehost-live } \& \text { scope }=\text { site }}$ 
Slovic, P. (1999). Trust, emotion, sex, politics, and science: Surveying the riskassessment battlefield<br />.19(4), 689-700. Retrieved from http://socserver.soc.iastate.edu/Sapp/Slovic.pdf

Stevens, J., Cornell, C. E., Story, M., French, S. A., Levin, S., Becentti, A., \& Reid, R. (1999). Development of a questionnaire to assess knowledge, attitudes, and behaviors in american indian children. The American Journal of Clinical Nutrition, 69(4), 773-781.

Trends in sexual risk behaviors among high school students --- united states, 1991--2001. Retrieved 2/16/2012, 2012, from http://www.cdc.gov/mmwr/preview/mmwrhtml/mm5138a2.htm

Whitbeck, L. B., Hoyt, D. R., Stubben, J. D., \& LaFromboise, T. D. (2001). Traditional culture and academic success among american indian children in the upper midwest. Journal of American Indian Education, 40(2), 48-60. Retrieved from http://ezproxy.library.und.edu/login?url=http://search.ebscohost.com/login.aspx?direct=tr $\underline{\text { ue } \& \mathrm{db}=\mathrm{fph} \& \mathrm{AN}=\mathrm{FPH} 73866 \& \text { site }=\text { ehost-live } \& \text { scope }=\text { site }}$ 
